\title{
Comprehensive study on structural and optical properties of Tm2O3 doped zinc silicate based glass-ceramics
}

\begin{abstract}
In this research, $\mathrm{Tm}_{2} \mathrm{O}_{3}$ doped zinc silicate based glass-ceramics were prepared by using conventional melt-quenching method and has been successfully derived from $\mathrm{ZnO}$-WRHA glasses with control heat treatment process. The formation of zinc silicate phase affected by heat treatment process was investigated using X-ray diffraction. Fourier transform infrared reflection spectroscopy (FTIR) analysis was used to determine the crystallization of $\mathrm{Zn}_{2} \mathrm{SiO}_{4}$ in the glass matrix. FTIR analysis showed the appearance of $\mathrm{Zn}_{2} \mathrm{SiO}_{4}$ and $\mathrm{SiO}_{2}$ bands that supported the formation of $\mathrm{Zn}_{2} \mathrm{SiO}_{4}$ crystal phase in the glass matrix. The optical absorption and energy band gap of the glass and glass-ceramics was investigated using UV-Vis spectroscopy. The absorption edge shows the movement towards longer wavelength with increasing heat treatment temperature. Besides, the energy band gap decreased with the progression of heat treatment. This ability to enhance optical properties in glass-ceramics was expected to have bright future in the opto-electronics devices.
\end{abstract}

Keyword: Tm2O3; Doped zinc silicate; Glass-ceramics 